\title{
ПРИМЕНЕНИЕ ОБЛЕПИХОВОГО ПЮРЕ В ТЕХНОЛОГИИ ПРОДУКТОВ ФУНКЦИОНАЛЬНОГО ПИТАНИЯ
}

\author{
M. V. Evsenina, I. S. Piturina, \\ o. V. Chernikova
}

\section{THE APPLICATION OF SEA BUCKTHORN PUREE IN FUNCTIONAL NUTRITION TECHNOLOGY}

Евсенина Марина Владимировна - канд. с.-х. наук, доц. каф. технологии общественного питания Рязанского государственного агротехнологического университета им. П.А. Костычева, г. Рязань. E-mail: marina.vlady@mail.ru

Питюрина Ирина Сергеевна - канд. с.-х. наук, ст. преп. каф. тылового обеспечения уголовноисполнительной системы Академии права и управления Федеральной службы исполнения наказания, г. Рязань. E-mail: piturina@yandex.ru

Черникова Ольга Владимировна - преп. каф. тылового обеспечения уголовно-исполнительной системы Академии права и управления Федеральной службы исполнения наказания, г. Рязань. E-mail: chernikova_olga@inbox.ru

Цель исследования - установление возможности применения и определение дозы внесения облепихового пюре в состав рецептуры запеканки из творога. Задачи исследования: установление оптимальной дозы введения облепихового пюре в рещептуру запеканки из творога; определение органолептических и фризико-химических показателей качества основного сырья и готовых изделий; определение выхода, пищевой и энергетической ценности запеканки. Для проведения исследования использовалось облепиховое пюре, полученное из свежих ягод. Изготовление облепихового пюре и пробная выработка запеканки из творога по вариантам опыта проводились в лабораторных условиях. Облепиховое пюре вносилось во время замеса ингредиентов. Доза внесения определялась на основании анализа опубликованных результатов ранее проведенных исследований. В опытных вариантах рецептуры запеканки была проведена частичная замена творога по вариантам опыта (10, 20 u 30 г). Показатели качества основного сырья
Evsenina Marina Vladimirovna - Cand. Agr. Sci., Assoc. Prof., Chair of Technology of Public Catering, Ryazan State Agrotechnological University named after P. A. Kostychev, Ryazan.

E-mail: marina.vlady@mail.ru

Pityurina Irina Sergeevna - Cand. Agr. Sci., Senior Lecturer, Chair of Logistic Support of Penal system, Academy of Law and Management, Federal Penitentionary System, Ryazan.

E-mail: piturina@yandex.ru

Chernikova Olga Vladimirovna - Teacher, Chair of Logistic Support of Penal system, Academy of Law and Management, Federal Penitentionary System,, Ryazan.

E-mail: chernikova_olga@inbox.ru

(творога и облепихового пюре) и готовых изделий определяли по стандартным общепринятьм методикам. Пищевая и энергетическая ценность запеканки определялись расчетным путем. Исследование показало, что использование облепихового пюре позволяет повысить биологическую ценность готового продукта, придав ему функциональные свойства, а также улучшить потребительские свойства запеканки. Результаты экспертизы качества запеканки из творога, проведенной в лабораторных условиях, по органолептическим и физико-химическим показателям позволили установить, что введение в рецептуру 20 г облепихового пюре приводит к получению полноценного продукта питания, обладающего фуннкциональньми свойствами за счет содержания витаминов, минеральных веществ, органических кислот и пищевых волокон.

Ключевые слова: облепиха, пюре, творог, запеканка, качество, состав, пищевая ценность, функциональные свойства, витамины, минеральные вещества. 
The purpose of the study was establishing the possibility of using and determining the dose of sea buckthorn puree in the recipe of cottage cheese casserole. The research problems were the establishment of an optimum dose of introduction of seabuckthorn puree to the compounding of baked pudding from cottage cheese; the definition of organoleptic and physical and chemical indicators of the quality of the main raw materials and finished products; the definition of the exit, nutrition and power value of baked pudding. For carrying out the research the sea-buckthorn puree received from fresh berries was used. The production of seabuckthorn puree and the process of the development of baked pudding from cottage cheese by the options of the experiment were carried out in vitro. Sea-buckthorn puree was brought during the batch of the ingredients. The dose of adding was defined on the basis of the analysis of published results of the researches conducted earlier. In test options of the compounding of baked pudding partial replacement of cottage cheese by test options (10, 20 and $30 \mathrm{~g}$ ) was made. The indicators of the quality of the main raw materials (cottage cheese and sea-buckthorn puree) and finished products were determined by the standard techniques. The nutrition and power value of baked pudding were defined by the settlement way. The research showed that using sea-buckthorn puree allowed to increase biological value of ready-made product, giving it functional properties, and also to improve consumer properties of baked pudding. The results of the expertise of the quality of baked pudding from cottage cheese carried out in vitro on organoleptic and physical and chemical indicators allowed to state that the introduction of $20 \mathrm{~g}$ of sea-buckthorn puree to the compounding led to receiving full-fledged food product possessing functional properties due to the content of vitamins, mineral substances, organic acids and food fibers.

Keywords: sea buckthorn, puree, cottage cheese, casserole, quality, composition, nutritional value, functional properties, vitamins, minerals.

Введение. Основной целью государственной политики в области здорового питания населения в последние годы является разработка и внедрение продуктов функционального назначения. Целесообразно обогащать продукты питания повседневного спроса, так как они наиболее востребованы широким кругом потребителей.
В последние годы отмечен активный рост интереса потребителей к группе молочных продуктов функциональной направленности, это связано с заботой о здоровье большинства потребителей и тенденциями рационального и функционального питания. Большой популярностью у потребителей пользуются кисломолочные продукты, в частности творог и творожные продукты. Они в разных формах входят в рацион почти $80 \%$ населения. Значительный интерес с точки зрения обогащения представляют творог и творожные продукты, источники полноценного и легкоусвояемого белка, рекомендованные для питания детей младшего возраста, пожилых и престарелых людей, страдающих различными нарушениями пищеварения [5].

Облепиховое пюре является хорошим физиологически функциональным наполнителем для многих кулинарных изделий и десертов. Применение облепихового пюре в технологии творожных продуктов способствует расширению их ассортимента, обогащает витаминноминеральный состав белкового продукта, улучшает вкус и цвет, не меняя при этом его консистенцию [1].

Плоды облепихи богаты биологически активными веществами и обладают высокими товарно-технологическими свойствами.

Цель исследования: совершенствование рецептуры запеканки из творога путем обогащения облепиховым пюре для придания готовому продукту функциональных свойств.

Исходя из цели, были поставлены следующие задачи: установление оптимальной дозы введения облепихового пюре в рецептуру запеканки из творога; определение органолептических и фризико-химических показателей качества основного сырья и готовых изделий; определение выхода, пищевой и энергетической ценности запеканки.

Объекты и методы исследования. Введение облепихового пюре в состав рецептуры запеканки проводилось путем частичной замены творога.

Контрольный образец был изготовлен по рецептуре № 326 «Запеканка из творога» из сборника рецептур блюд и кулинарных изделий для предприятий общественного питания под редакцией Л.Е. Голуновой. Для исследования были выбраны варианты опыта: замены творога на облепиховое пюре в рецептуре в количестве 10; 20; 30 г соответственно. Рецептура запеканки по вариантам опыта представлена в таблице 1. 
Рецептура запеканки по вариантам опыта

\begin{tabular}{|l|c|c|c|c|}
\hline \multirow{2}{*}{ Сырье } & \multicolumn{4}{|c|}{ Норма закладки сырья, г } \\
\cline { 2 - 5 } & Контроль & Образец № 1 & Образец № 2 & Образец № 3 \\
\hline Творог & 136 & 126 & 116 & 106 \\
\hline Мука пшеничная & 10 & 10 & 10 & 10 \\
\hline Облепиховое пюре & - & 10 & 20 & 30 \\
\hline Сахар & 15 & 15 & 15 & 15 \\
\hline Яйца & 7 & 7 & 7 & 7 \\
\hline Маргарин столовый & 5 & 5 & 5 & 5 \\
\hline Сухари & 5 & 5 & 5 & 5 \\
\hline Сметана & 5 & 5 & 5 & 150 \\
\hline $\begin{array}{l}\text { Масса готовой } \\
\text { запеканки }\end{array}$ & 150 & 150 & 150 & 5 \\
\hline
\end{tabular}

Технологическая схема приготовления облепихового пюре представлена на рисунке 1. Способ получения пюре из облепихи предусматривает отделение ягод от веточек, мойку, инспекцию, бланширование ягод и протирание. Бланширование осуществляется при температуре 90-100 ${ }^{\circ} \mathrm{C}$ в течение 5-7 мин в воде, взятой в количестве 10-15 \% от массы ягод. Под воздей-

ствием высокой температуры белки протоплазмы коагулируют, что облегчает протирание. Целостность сырья при этом нарушается, и в бланшировочную воду переходят экстрактивные вещества сырья. Повреждение целостности кожиц ягод происходит в результате вскипания сока в подкожном слое.

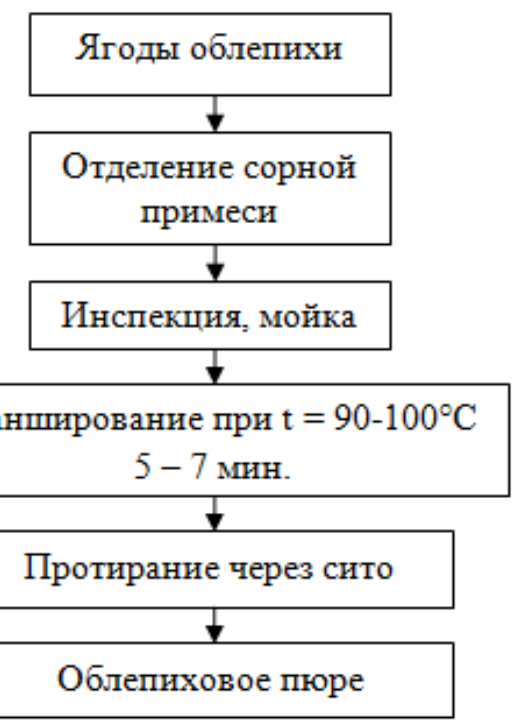

Puс. 1. Технологическая схема приготовления облепихового пюре

Воду, которую используют для бланширования, добавляют при протирании. Из-за разбавления водой снижается содержание массовой доли растворимых сухих веществ, сахаров, органических кислот, витаминов, что приводит к ухудшению качества пюре. Поэтому несколько порций ягод облепихи бланшируется в одной порции воды. Выход пюре при таком способе подготовки ягод облепихи составляет 65-70\%.

Опытные и контрольные образцы готовились из одних партий сырья. Исследование проводилось по стандартным, общепринятым методикам.

Отбор и подготовка проб творога к анализу проводились по ГОСТ 3622- 68 «Молоко и молочные продукты. Отбор проб и подготовка к их 
испытанию». Органолептические показатели творога определялись по ГОСТ 31453-2013 «Творог. Технические условия». Определение кислотности творога проводилось по ГОСТ 3624-92 «Молоко и молочные продукты. Титриметрические методы определения кислотности». Определение массовой доли влаги творога осуществлялось в соответствии с ГОСТ 362673 «Молоко и молочные продукты. Методы определения влаги и сухого вещества». Массовая доля жира творога определялась по ГОСТ 586790 «Молоко и молочные продукты. Методы определения жира».

Показатели качества облепихового пюре оценивались на соответствие требованиям ГОСТ 32742-2014 «Полуфрабрикаты. Пюре фрруктовые и овощные консервированные асептическим способом. Технические условия».
Массовая доля титруемых кислот определялась в пересчете на яблочную.

Органолептическая оценка готовых образцов запеканки из творога проводилась согласно ГОСТ 31986-2012 «Услуги общественного питания. Метод органолептической оценки качества продукции общественного питания». Определение физико-химических показателей качества запеканки из творога (влажности, кислотности, массовой доли жира) проводилось по «Методическим указаниям по лабораторному контролю качества продукции общественного питания» [2].

Показатели витаминно-минерального состава и энергетической ценности устанавливались расчетным методом.

Результаты исследования и их обсуждение. Показатели качества творога, используемого в качестве основного сырья для изготовления запеканки, представлены в таблице 2.

Таблица 2

\section{Показатели качества творога}

\begin{tabular}{|l|c|c|}
\hline \multicolumn{1}{|c|}{ Показатель } & $\begin{array}{c}\text { Требования } \\
\text { по ГОСТ 31453-2013 }\end{array}$ & Данные исследования \\
\hline $\begin{array}{l}\text { Консистенция } \\
\text { и внешний вид }\end{array}$ & $\begin{array}{c}\text { Мягкая, мажущаяся или рассып- } \\
\text { чатая с наличием или без ощу- } \\
\text { тимых частиц молочного белка }\end{array}$ & $\begin{array}{c}\text { Мягкая, мажущаяся, } \\
\text { с незначительным количест- } \\
\text { вом ощутимых частиц молоч- } \\
\text { ного белка }\end{array}$ \\
\hline Вкус и запах & $\begin{array}{c}\text { Чистые, кисломолочные, без по- } \\
\text { сторонних привкусов и запахов }\end{array}$ & $\begin{array}{c}\text { Чистые, кисломолочные, } \\
\text { безоронних привкусов } \\
\text { и запахов }\end{array}$ \\
\hline Цвет & $\begin{array}{c}\text { Белый или с кремовым оттенком, } \\
\text { равномерный по всей массе }\end{array}$ & $\begin{array}{c}\text { Белый, с легким кремовым } \\
\text { оттенком, равномерный } \\
\text { по всей массе }\end{array}$ \\
\hline Массовая доля влаги, \% & Не более 73,0 & 71,2 \\
\hline Кислотность, ${ }^{\circ}$ Т & Не более 220 & 204 \\
\hline Массовая доля жира, \% & ненее 9,0 & 9,1 \\
\hline
\end{tabular}

По органолептическим и физико-химическим показателям данное сырье полностью соответствует требованиям ГОСТ 31453-2013 «Творог. Технические условия».

Показатели качества облепихового пюре, используемого для проведения эксперимента, представлены в таблице 3.
На основании полученных данных можно сделать вывод, что добавка может быть использована в качестве рецептурного компонента при изготовлении запеканки из творога. 


\section{Показатели качества облепихового пюре}

\begin{tabular}{|c|c|c|}
\hline Показатель & Требования ГОСТ 32742-2014 & Значения показателя \\
\hline Внешний вид & $\begin{array}{c}\text { Однородная пюреообразная текучая } \\
\text { масса без частиц, волокон, кожицы, } \\
\text { семян, плодоножек и листьев }\end{array}$ & $\begin{array}{c}\text { Однородная пюреобразная } \\
\text { текучая масса }\end{array}$ \\
\hline Вкус и запах & $\begin{array}{c}\text { Хорошо выраженные, свойственные } \\
\text { фруктам (овощам), прошедшим тепло- } \\
\text { вую обработку, из которых изготовле- } \\
\text { но пюре }\end{array}$ & $\begin{array}{c}\text { Хорошо выраженной облепихи, } \\
\text { прошедшей тепловую обработку } \\
\text { из которого изготовлено пюре }\end{array}$ \\
\hline Консистенция & Пюреобразная, текучая масса & Пюреобразная, текучая масса \\
\hline Цвет & $\begin{array}{c}\text { Однородный по всей массе, свойст- } \\
\text { венный цвету использованных зрелых } \\
\text { фруктов или овощей, прошедших теп- } \\
\text { ловую обработку }\end{array}$ & $\begin{array}{c}\text { Однородный по всей массе, } \\
\text { свойственный цвету использо- } \\
\text { ванных зрелых плодов облепихи, } \\
\text { прошедших тепловую обработку }\end{array}$ \\
\hline $\begin{array}{l}\text { Посторонние } \\
\text { примеси }\end{array}$ & Не допускаются & Не обнаружено \\
\hline $\begin{array}{l}\text { Массовая доля } \\
\text { растворимых сухих } \\
\text { веществ, \% }\end{array}$ & Не менее 6 & 9,2 \\
\hline $\begin{array}{l}\text { Массовая доля тит- } \\
\text { руемых кислот, \% }\end{array}$ & Не менее 0,8 & 1,3 \\
\hline
\end{tabular}

Технология приготовления запеканки из творога состоит из ряда технологических операций (рис. 2). Протертый творог смешивают с просеянной мукой, яйцами, сахаром, солью и облепиховым пюре. Подготовленную массу выкладывают слоем 3-4 см в смазанную маргарином и посыпанную сухарями форму. Поверхность массы разравнивают, смазывают сметаной, запекают в жарочном шкафу 20-30 мин до образования на поверхности румяной корочки. При отпуске запеканку из творога нарезают на куски прямоугольной формы [3].

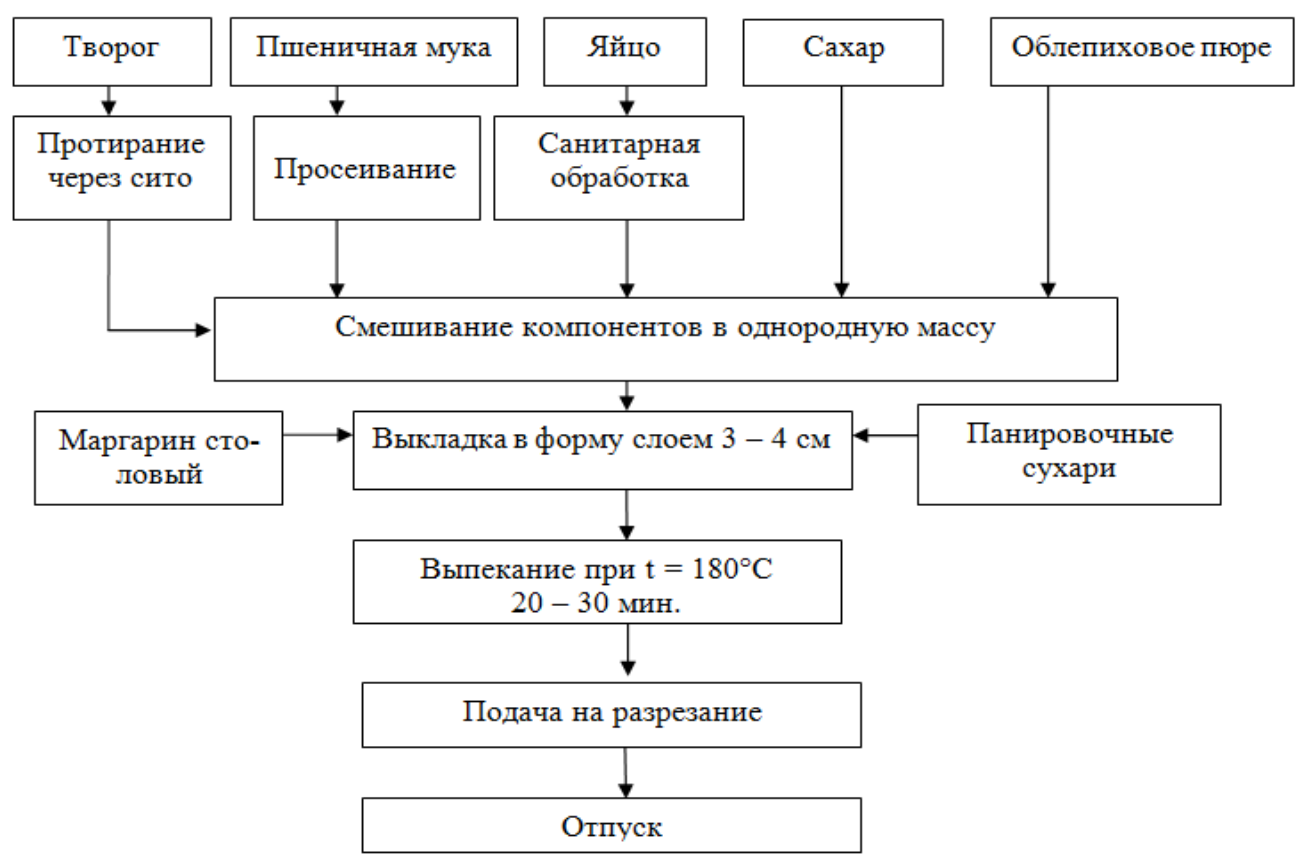

Puc. 2. Технологическая схема приготовления запеканки из творога с облепиховым пюре 
Вестник КрасТАY., 2020. № 5

Оценка органолептических показателей качества запеканки проводилась по 5-балльной шкале. Результаты дегустационной оценки представлены в таблице 4.
При введении в состав рецептуры облепихового пюре в разных дозах форма и состояние поверхности запеканки из творога соответствовали норме. Внешний вид образцов запеканки представлен на рисунках 3,4 .

Таблица 4

\section{Результаты дегустационной оценки образцов запеканки из творога}

\begin{tabular}{|l|c|c|c|c|}
\hline \multirow{2}{*}{\multicolumn{1}{|c|}{ Показатель }} & \multicolumn{4}{|c|}{ Оценка изделия, балл } \\
\cline { 2 - 5 } & Контроль & Образец № 1 & Образец № 2 & Образец № 3 \\
\hline Внешний вид & 4,8 & 4,6 & 4,9 & 4,3 \\
\hline Консистенция & 4,5 & 4,5 & 4,9 & 4,7 \\
\hline Вкус & 4,7 & 4,5 & 4,9 & 4,2 \\
\hline Запах & 4,6 & 4,4 & 4,9 & 4,4 \\
\hline Цвет & 4,8 & 4,6 & 4,9 & 3,8 \\
\hline Общая оценка & 4,7 & 4,5 & 4,9 & 4,3 \\
\hline
\end{tabular}

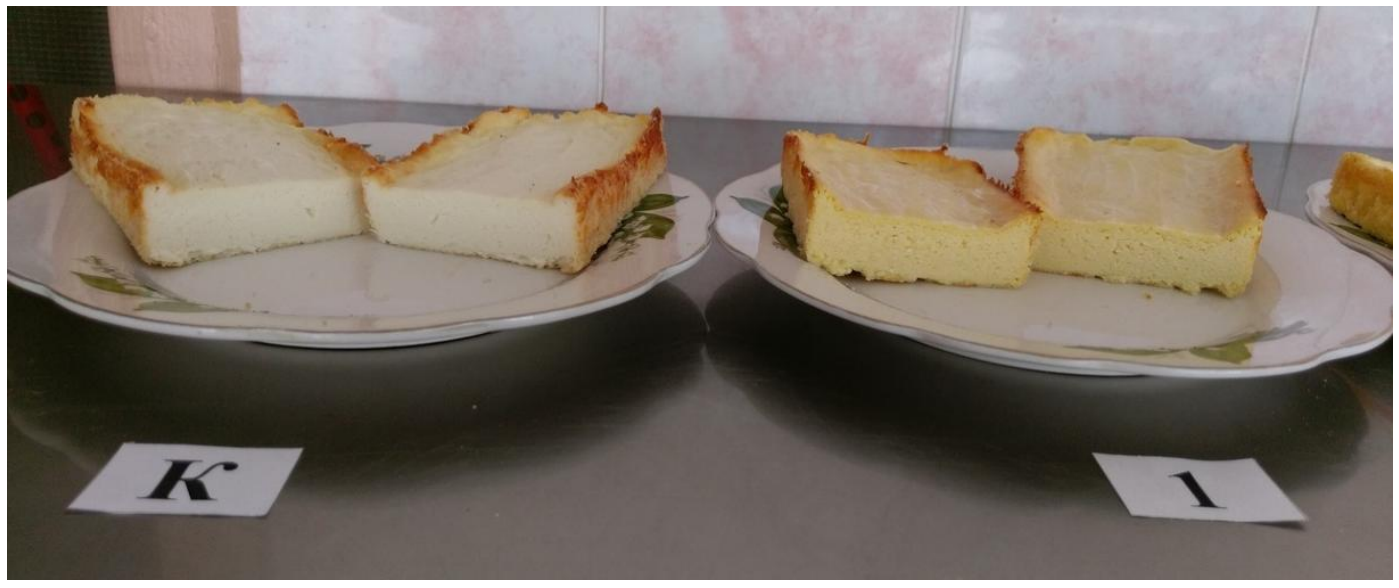

Puс. 3. Внешний вид исследуемых образцов запеканки из творога: контрольный образец и опытный образец № 1

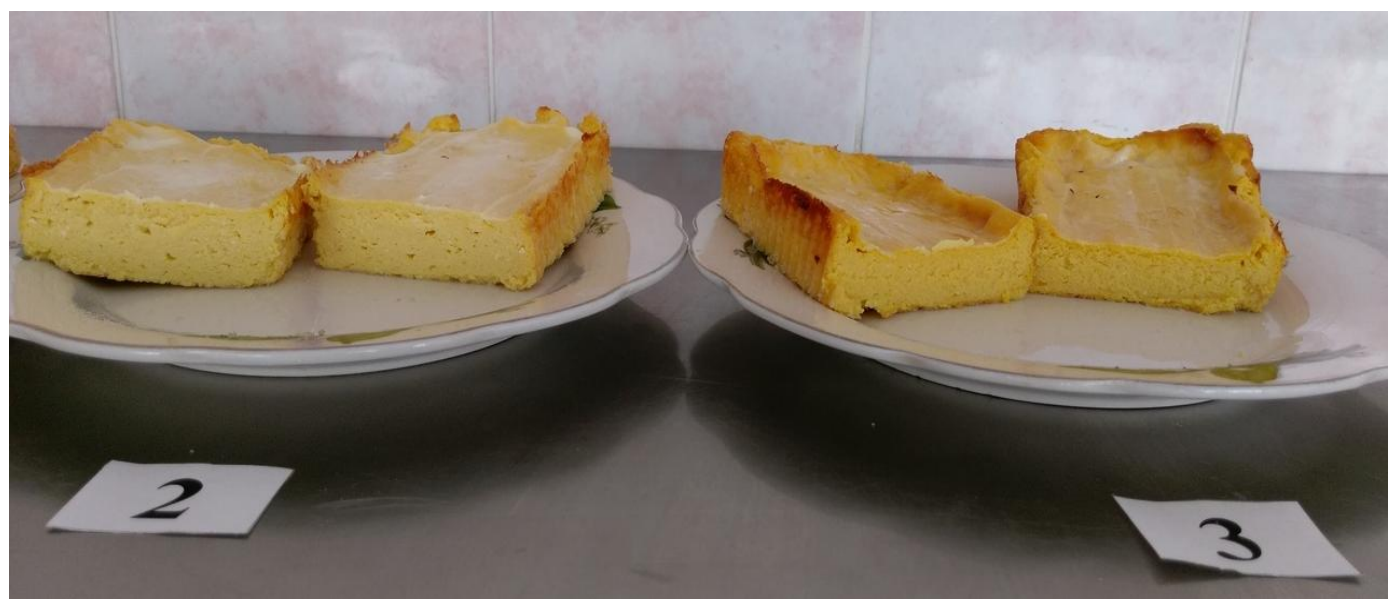

Puc. 4. Внешний вид исследуемых образцов запеканки из творога (слева направо): опытный образец № 2 и опытный образец № 3 
По результатам органолептической оценки было замечено, что замена 10 г творога на облепиховое пюре практически не повлияла на органолептические показатели блюда. Введение облепихового пюре лишь придало легкий привкус запеканке.

Опытный образец с добавлением 20 г облепихового пюре получил наиболее высокие баллы. Это изделие имело равномерную румяную корочку на поверхности, сладкий творожный вкус с привкусом облепихи, мягкую, однородную, пропеченную консистенцию, а также внешний вид, соответствующий используемым сырьевым компонентам.

С увеличением дозы замены творога на облепиховое пюре до 30 г усилился вкус и запах добавки, цвет приобрел более интенсивный оттенок, вкус стал излишне кислый.
По результатам дегустационной оценки лучшими был признан опытный образец № 2, получивший 4,9 балла. Наименьшее количество баллов (4,3 балла) получили опытный образец № 3 из-за кислого вкуса.

Изучение органолептических показателей изделий позволило определить оптимальную дозу замены творога на облепиховое пюре. Наиболее удачным признан образец, в котором была произведена замена 20 г сырья на облепиховое пюре. Этот образец был выбран для проведения дальнейших исследований.

В контрольном и лучшем по органолептическим показателям опытном образцах запеканки из творога были определены физико-химические показатели (табл. 5).

Таблица 5

\section{Физико-химические показатели качества запеканки из творога}

\begin{tabular}{|l|c|c|}
\hline \multirow{2}{*}{ Показатель } & \multicolumn{2}{|c|}{ Значение показателя } \\
\cline { 2 - 3 } & Контрольный образец & Опытный образец № 2 \\
\hline Массовая доля влаги, \% & 58,8 & 59,6 \\
\hline Кислотность, ${ }^{\circ} \mathrm{T}$ & 182 & 191 \\
\hline
\end{tabular}

Из полученных данных видно, что кислотность опытного образца возрастает на $9{ }^{\circ} \mathrm{T}$. Массовая доля влаги в опытном образце увеличилась на 0,8\%. Это связано с более высоким содержанием сухих веществ в твороге по сравнению с облепиховым пюре.

Величина потерь массы изделий при тепловой обработке является важным показателем. Результаты данных исследований представлены в таблице 6.

Выход запеканки с облепиховым пюре увеличился на 5 г, потери при тепловой обработке уменьшились на 2,7\%.
Пищевая ценность запеканки из творога представлена в таблице 7.

Энергетическая ценность опытного образца на 16,88 ккал ниже, чем у контрольного. При этом массовая доля белка снизилась на $3,27 \%$, жира - на 0,69 \%. Содержание углеводов увеличилось на 0,50 \%. Изменения состава связаны с уменьшением содержания в рецептуре блюда творога. Снижение массовой доли жира у опытного образца объясняется тем, что в облепихе большая часть жира содержится в косточках, которые были извлечены в процессе производства облепихового пюре.

Потери массы запеканки из творога при тепловой обработке

\begin{tabular}{|l|c|c|}
\hline \multicolumn{1}{|c|}{ Образец } & Потери & $\begin{array}{c}\text { Выход } \\
\text { готовых изделий, г }\end{array}$ \\
\hline Контроль & при тепловой обработке, \% & 150 \\
\hline Опытный вариант № 2 & 18,0 & 155 \\
\hline
\end{tabular}


Пищевая ценность запеканки из творога

\begin{tabular}{|l|c|c|}
\hline \multicolumn{1}{|c|}{ Показатель } & Контроль & Опытный образец \\
\hline Белок, \% & 26,21 & 22,94 \\
\hline Жир, \% & 17,80 & 17,11 \\
\hline Углеводы, \% & 27,51 & 28,01 \\
\hline Пищевые волокна, \% & 0,58 & 0,98 \\
\hline Зола, \% & 1,68 & 1,63 \\
\hline Минеральные вещества, мг\%: & & 124,54 \\
\hline Na & 111,64 & 205,97 \\
\hline K & 189,77 & 244,89 \\
\hline Са & 243,29 & 37,77 \\
\hline Mg & 36,37 & 290,74 \\
\hline P & 332,94 & 1,34 \\
\hline Fе & 1,14 & \\
\hline Витамины, мг\%: & & 94,00 \\
\hline А & 84,00 & 0,13 \\
\hline В1 & 0,12 & 0,48 \\
\hline В & 0,43 & 1,01 \\
\hline РР & 1,02 & 40,59 \\
\hline С & 0,7 & $372,36(1559,0)$ \\
\hline Энергетическая ценность, ккал (кДж) & $389,24(1629,7)$ & \\
\hline
\end{tabular}

Введение в состав запеканки из творога облепихового пюре привело к увеличению содержания минеральных веществ: натрия, калия, кальция, магния и железа.

Содержание витамина C возросло в 58 раз. Витамин С является сильным антиоксидантом, участвует в синтезе белков и жиров, обладает антиканцерогенным действием, влияет на тромбопоэз, способствует сохранению целостности соединительной ткани, благоприятно воздействует на иммунную систему, т. е. выполняет самые разнообразные фрункции в организме человека [4].

Использование облепихового пюре способствует повышению биологической ценности продукта и приданию ему фуункциональных Свойств.

Заключение. Использование облепихового пюре позволит обогатить состав запеканки из творога витаминами, органическими кислотами, минеральными веществами и пищевыми волокнами, улучшить потребительские свойства готовых изделий. Регулярное употребление в пищу запеканки из творога с облепиховым пюре в со- ставе рационов разных возрастных групп здоровых потребителей позволит обеспечить организм биологически активными соединениями с целью профилактики возникновения и развития алиментарных заболеваний.

Таким образом, по органолептическим и физико-химическим показателям качества запеканки из творога оптимальным вариантом следует признать замену 20 г творога на облепиховое пюре.

\section{Литература}

1. Евсенина М.В. Экспертиза качества вареников с творогом, представленных на потребительском рынке г. Рязани // Актуальные вопросы материально-технического снабжения органов и учреждений уголовноисполнительной системы: мат-лы dсерос. науч.-практ. круглого стола. Рязань, 2017. C. $140-146$.

2. Евсенина М.В., Никитов С.В. Лабораторный практикум по товароведению продовольственных товаров. Рязань, 2018. 227 с. 
3. Евсенина М.В., Никитов С.В. Практикум по безопасности продовольственного сырья и продуктов питания. Рязань, 2019. 95 с.

4. Никитов С.В., Евсенина М.В., Самойлова М.В. Целесообразность использования пищевой добавки пектин в рецептуре блюда «Творог в желе» // Инновационное развитие современного агропромышленного комплекса России: мат-лы национальной науч.практ. конф. Рязань, 2016. С. 156-160.

5. Никитов С.В., Евсенина М.В. Практикум по организации производства и управлению качеством продукции в общественном питании. Рязань, 2019. 155 с.

\section{Literatura}

1. Evsenina M.V. Jekspertiza kachestva varenikov s tvorogom, predstav-lennyh na potrebitel'skom rynke g. Rjazani // Aktual'nye voprosy material'no-tehnicheskogo snabzhenija orga- nov i uchrezhdenij ugolovno-ispolnitel'noj sistemy: mat-ly Vseros. nauch.-prakt. kruglogo stola. Rja-zan', 2017. S. 140-146.

2. Evsenina M.V., Nikitov S.V. Laboratornyj praktikum po tovarovedeniju prodovol'stvennyh tovarov. Rjazan', 2018. $227 \mathrm{~s}$.

3. Evsenina M.V., Nikitov S.V. Praktikum po bezopasnosti prodovol'stvennogo syr'ja i produktov pitanija. Rjazan', $2019.95 \mathrm{~s}$.

4. Nikitov S.V., Evsenina M.V., Samojlova M.V. Celesoobraznost' ispol'zovanija pishhevoj dobavki pektin v recepture bljuda «Tvorog v zhele» // Innovacionnoe razvitie sovremennogo agropromyshlennogo kompleksa Rossii: mat-ly nacional'noj nauch.-prakt. konf. Rjazan', 2016. S. 156-160.

5. Nikitov S.V., Evsenina M.V. Praktikum po organizacii proizvod-stva i upravleniju kachestvom produkcii $v$ obshhestvennom pitanii. Rjazan', 2019. 155 s. 